\title{
FORMAÇÃO INICIAL E INCLUSÃO NA EDUCAÇÃO INFANTIL: O TRABALHO DOCENTE A PARTIR DA ÓTICA DE FUTUROS PROFESSORES
}

\author{
Marina Sampaio da Silva ${ }^{1}$, Renata Portela Rinaldi ${ }^{2}$ \\ 1 Curso de Licenciatura em Pedagogia, FCT/UNESP. Departamento de Educação, FCT/UNESP. E-mail: \\ mah_sampaio10@hotmail.com. PIBIC/CNPq
}

\begin{abstract}
RESUMO
Nas últimas décadas, uma questão que tem promovido intensos debates no meio educacional e gerado uma série de conflitos no cotidiano escolar é a proposta de inclusão. Nessa perspectiva, novos caminhos precisam ser trilhados tanto para as escolas regulares quanto para as instituições de educação infantil, cuja função não é exclusivamente a de preparar a criança para frequentar o Ensino Fundamental, mas a de compreender que o educar significa propiciar situações de cuidados, brincadeiras e aprendizagens orientadas de forma integrada e que possam contribuir para o desenvolvimento das capacidades infantis de relação interpessoal, de respeito e confiança, (BRASIL, 1998). Nesse cenário, o presente trabalho busca investigar as impressões de futuros professores do curso de Licenciatura em Pedagogia da FCT/Unesp, sobre a docência na Educação Infantil com Estudantes Público Alvo da Educação Especial (EPAEE).
\end{abstract}

Palavras-chave: Formação inicial. Estágio supervisionado. Inclusão. Educação infantil. Criança.

\section{INTRODUÇÃO}

A Educação Infantil legalmente integra-se ao sistema de ensino desde 1996 (Lei de Diretrizes e Bases da Educação Nacional - LDB) e é considerada a primeira etapa da educação básica que compreende as creches, para crianças até 3 anos e não considerada uma etapa obrigatória, porém é um direito de toda criança; e as pré-escolas, para crianças de 4 e 5 anos ${ }^{1}$.

Como tem se configurado o trabalho pedagógico com as crianças Estudantes Público Alvo da Educação Especial ${ }^{2}$ (EPAEE) nesse nível de ensino? E os professores estarão sendo preparados, durante a formação inicial, para trabalhar com esse público na faixa etária de 0 a 6 anos de idade? Como as práticas de ensino e o estágio supervisionado podem contribuir nesse processo de formação inicial? É este o tema central deste artigo. A partir da ótica dos futuros professores buscamos investigar como eles percebem a formação durante o curso de licenciatura para trabalhar com crianças EPAEE na Educação Infantil.

\footnotetext{
${ }^{1}$ Nos últimos anos, duas mudanças importantes foram introduzidas na educação infantil brasileira: a) a idade prevista para o término da pré-escola, alterada em 2006, que passou de 6 para 5 anos, antecipando a entrada no ensino fundamental; b) outra mudança, de 2009, determinou a obrigatoriedade de matrícula-frequência na pré-escola para crianças de 4 e 5 anos (ROSEMBERG, 2009).

${ }^{2} \mathrm{O}$ público alvo da Educação Especial na perspectiva da Educação Inclusiva são pessoas com deficiência, transtornos globais do desenvolvimento e altas habilidades/superdotação.
} 
O interesse surgiu devido ao fato de que, a primeira autora, enquanto futura professora e licencianda no curso de Pedagogia da Faculdade de Ciências e Tecnologia (FCT/Unesp), durante os Estágios Supervisionados realizados na Educação Infantil não teve contato com nenhum estudante incluso, porém há muita insegurança e medo quanto a expectativa de que após a conclusão do curso pode se deparar com crianças EPAEE no início do exercício profissional da docência. Além disso, porque sabemos que atualmente se exige que os professores apresentem e dominem um conjunto de capacidades, conhecimentos e ações para ensinar a todos os alunos e sejam proficientes no trabalho em grupo, com metodologias ativas numa perspectiva inclusiva.

\section{O TRABALHO EMPÍRICO}

Esta pesquisa se pauta em uma abordagem qualitativa, na qual se defende a ideia de que, em se tratando de fenômenos humanos e sociais, "[...] interessa mais compreender e interpretar seus conteúdos do que descrevê-los, explicá-los" (TOZONI-REIS, 2009, p. 5). Deste modo, o pesquisador que opta pela área de educação, tem papel fundamental e de grande responsabilidade, pois não basta apenas observar os fatos é necessário interpretar os fenômenos obtidos.

Para Tozoni-Reis (2009) a pesquisa é um processo de investigação para produzir conhecimentos que auxiliem na compreensão de uma dada realidade ou aspectos dela. Além disso, traz duas concepções distintas sobre pesquisa e que podem auxiliar no entendimento de tal processo. Segundo Minayo (2002), a pesquisa pode se constituir como sendo "conceitual", uma prática social que vincula pensamento e ação. Já para Gil (1996), a pesquisa é "operacional”, necessitando do uso de conhecimentos, métodos, técnicas e procedimentos científicos. Apesar de ambas não serem semelhantes quanto à definição, possuem em comum a associação da pesquisa com o conhecimento.

Assim, o objetivo deste estudo foi analisar as respostas de alunos do curso de licenciatura em Pedagogia da Faculdade de Ciências e Tecnologia da Universidade Estadual Paulista (FCT/UNESP), sobre questões específicas relativas à sua formação para o exercício da docência na educação infantil e com crianças EPAEE. Estas questões centram-se em três aspectos: relação teoria-prática, conteúdo e impacto do curso na formação profissional para o trabalho com a criança EPAEE.

A amostra foi constituída por 29 estudantes do 3 으 e 4 으 ano do referido curso, que responderam em outubro de 2012 e junho de 2013, a um questionário. Dos 29 alunos, 
aproximadamente $90 \%$ são egressos de escolas públicas, apenas um era do gênero masculino e as demais do gênero feminino; 20 estudavam no período vespertino e 10 no noturno. Do total de alunos, 19 tinham algum tipo de bolsa de estudo ${ }^{3}, 4$ trabalhavam na área da educação com estágio remunerado e os demais estavam vinculados a outras atividades de serviço.

Os dados foram tratados agrupando as respostas considerando os três aspectos abordados. Dessa forma, por meio da organização discursiva das respostas dos questionários construiremos uma ideia comum dos pensamentos expostos pelos participantes, tendo assim, uma expressão dos estudantes em relação às questões.

\section{APRESENTAÇÃO/DISCUSSÃO DOS RESULTADOS}

Sabemos que a formação inicial é um ciclo importante da preparação profissional do futuro professor e deveria se constituir como um momento privilegiado para a ruptura de crenças, reflexão de experiências de aprendizagens e de ensino. Contudo, às vezes as crenças e experiências estão tão arraigadas e a distância entre a teoria e o futuro contexto de atuação profissional é tão grande que a formação inicial se torna um antídoto fraco para propiciar um mínimo de mudança nos licenciandos.

Muitas investigações têm apontando uma insatisfação tanto de instâncias políticas, como dos professores em exercício na escola e dos próprios formadores da universidade a respeito da capacidade dos cursos de licenciatura para dar respostas às necessidades da profissão docente na atualidade. São inúmeras as críticas à excessiva burocratização, o distanciamento entre teoria e prática na organização dos currículos, à fragmentação do conhecimento trabalhado, à escassa vinculação com as escolas etc.

No caso específico de nosso estudo, após levantamento bibliográfico realizado nas produções anuais da Reunião Anual da Associação Nacional de Pós-Graduação e Pesquisa em Educação (ANPED), no período de 2000 a 2011, revelou que do total de 3820 trabalhos completos, 885 pôsteres e 116 trabalhos encomendados publicados nos Grupos de Trabalho (GTs - Estado e Política Educacional; Educação da Criança de 0 a 6 anos; Formação de Professores; e Educação Especial) apenas 8 abordavam alguns aspectos do tema investigado. Contudo, não foi identificada nenhuma experiência que versasse sobre a análise do currículo da formação inicial no curso de Pedagogia e a articulação teoria e prática durante os estágios supervisionados de educação infantil

\footnotetext{
${ }^{3}$ Por estarem vinculados a projeto de pesquisa (Iniciação Científica - PIBIC/CNPq ou FAPESP), iniciação a docência (PIBID/CAPES) ou de extensão (PROEX ou Núcleo de Ensino).
} 
para atuar com crianças EPAEE. Comumente as experiências versam sobre casos específicos de intervenção para o trabalho com determinadas deficiências e majoritariamente voltados para o ensino fundamental ou sobre a formação continuada de professores.

Ampliando esse escopo de análise, ao buscarmos documentos oficiais verificamos aspectos gerais que devem ser contemplados no currículo da formação inicial, de modo que a universidade tem autonomia para elaborar sua proposta pedagógica desde que respeite o que foi instituído por meio das "Diretrizes Curriculares Nacionais para o Curso de Graduação em Pedagogia" (BRASIL, 2006). Assim, no currículo do curso de Pedagogia da FCT/UNESP identificamos por meio dos núcleos básico, de aprofundamento e integrador conteúdos voltados para a atuação na educação infantil e a educação inclusiva.

Ao analisarmos os documentos norteadores sobre o trabalho docente nessa etapa da educação básica, ou seja, a educação infantil, observamos que nem mesmo os principais documentos oficiais específicos para esse nível de ensino, bem como as orientações da atual política de Educação Especial na perspectiva da Educação Inclusiva há indicações sobre o que e como formar o professor generalista (pedagogo) para atuar com a criança pequena EPAEE.

Nesse sentido, devido à autonomia da universidade para a organização curricular, ao perfil dos seus formadores e considerando o perfil diversificado de estudantes que adentram as instituições de ensino básico atualmente é possível inferir que a universidade tem re-significado as orientações oficiais e criado estratégias para ensinar a profissão aos licenciandos de modo a preparar-lhes para atuar com as diferenças de todos os alunos?

Nosso estudo indicou que todos os 29 respondentes cursaram disciplinas teóricas voltadas para a educação infantil e realizaram estágio supervisionado em salas com crianças na faixa etária de 0 a 3 anos, 97\% realizou a disciplina voltada para educação inclusiva e 34,4\% a de Libras.

No que se refere ao estágio, 2 licenciandos encontraram crianças EPAEE na instituição sendo uma com deficiência intelectual e a outra com deficiência física - cadeirante; apenas 2 licenciandos estagiaram em salas que tinham um criança com deficiência intelectual e a outra com síndrome de Down. Esses últimos relatam a dificuldade de atuar com crianças incluídas, pois o conteúdo trabalhado no curso de licenciatura não previu procedimentos didáticos, teóricos e práticos que auxiliem o futuro professor a planejar o ensino que envolva a todos, especialmente a criança pequena.

Os conteúdos específicos, apesar de trabalhados nas disciplinas e reconhecidos pelos futuros professores como importantes, tem evidenciado a fragmentação da organização curricular 
entre as disciplinas fundamentantes e aquelas de prática ou, não têm se caracterizado como oportunidades de reflexão a partir da inserção no futuro contexto de atuação profissional, ou ainda são estudados de modo aligeirado, como se observa nos relatos de Q1, Q7, Q10 e Q15.

Não percebi o apoio teórico para trabalhar com criança com deficiência, pois o estágio de 0 a 3 anos foi antes da disciplina de Educação Inclusiva. (Q1, 10/2012)

Houveram alguns textos que davam uma noção de como era estagiar em uma sala de educação infantil com crianças com deficiências, mas, não foi algo que esclarecesse dúvidas (Totalmente as nossas dúvidas). (Q7, 10/2012)

Durante o curso estudamos: Libras, problemas de desenvolvimento, os tipos de deficiências existentes e alguns suportes pedagógicos para o trabalho em sala de aula. No entanto, todos os conteúdos foram trabalhados de modo superficial e aligeirado e não me ajudaram a perceber como podem ser usados na prática quando fui para o estágio. (Q10, 10/2012)

Tivemos a disciplina de Fundamentos da educação Inclusiva, mas não fiz intervenção e não usei esse conteúdo fora da universidade. (Q15, 10/2012)

É possível verificar, a partir dos relatos dos futuros professores uma significativa dissociação entre teoria (conteúdo do curso) e prática (de estágio) na formação inicial, a primazia pelo ensino do conteúdo deslocado da reflexão sobre a escola contemporânea, sobre os alunos reais, sobre as condições de trabalho etc. Desse modo, a construção do conhecimento prático sobre como ensinar na educação infantil fica apenas para o futuro professor que sozinho precisará encontrar o melhor caminho para ensinar seus futuros alunos e desenvolver uma competência prática própria da docência.

Por essa razão, quando inquiridos sobre o impacto da formação inicial para a preparação profissional, os licenciandos apontam lacunas que precisarão urgentemente ser consideradas pelas instituições formativas, a saber:

Poderíamos ter aulas sobre algumas deficiências encontradas em sala de aula e também poderíamos ter estágio apenas em salas que tem crianças deficientes. Com isso, teríamos um auxílio para trabalharmos com a inclusão escolar. (Q4, 06/2013)

Acredito que eu deveria ter aprendido o que fazer na prática com cada tipo de deficiência, pois cada deficiente tem uma necessidade a ser entendida, exemplo: com um aluno que tem paralisia cerebral (em que já trabalhei) é 
necessário trocar fralda, ensiná-lo a comer sozinho e até mesmo colocar e tirar as talas da perna e do braço. (Q9, 06/2013)

Não aprendi a como cuidar adequadamente de crianças com diferentes deficiências. Além disso, o foco das disciplinas que me aportaram teoricamente esteve embasado mais nas séries iniciais do que na creche e pré-escola. (Q2, 10/2012)

O curso tem uma fundamentação muito teórica, os estágios não são suficientes para uma aproximação com crianças com deficiência. Acredito que talvez poderia ser possibilitado algum trabalho de campo dentro da própria disciplina, para que se possa colocar em prática o que foi visto em sala; voltando assim nosso olhar a uma criticidade, a uma análise sobre o tema. (Q3, 10/2012)

Verificamos por meio dos relatos de Q4, Q9, Q2 e Q3, que também ecoam nas respostas dos demais respondentes, a necessidade de reduzir o abismo que separa as concepções teóricas e conteudistas dos princípios de intervenção da prática cotidiana. A revisão do currículo e a aproximação da universidade com as instituições de educação básica para o estabelecimento de parcerias significativas de ensino da profissão aos licenciandos pode ser uma alternativa promissora. Por outro lado, o ensino dos conteúdos na universidade deve primar, também, pela aprendizagem de habilidades práticas que auxiliem o futuro professor a percebem e fazer uso desse conhecimento para a resolução de problemas/situações concretas de ensino.

Dessa forma, percebemos que há um grande caminho a se percorrer para a formação de um pedagogo capaz de aprender a profissão a partir de experiências concretas de ensino e com crianças EPAEE. Esse início pode estar na graduação, chamada de formação inicial, e se estender por toda a vida profissional, nas formações continuadas, oportunizadas pelas próprias escolas, ou por alguma outra agência ou grupo de profissionais.

\section{CONCLUSÕES}

Ao final dessa etapa da nossa pesquisa, depois de um minucioso exame, sobre o que os documentos oficiais trazem em relação à educação inclusiva no país, vimos que a educação básica é um direito assegurado por lei a todas às pessoas desde os 4 ano, e aqueles que necessitam de uma educação especial devem recebe-la como complementação ou suplementação ao ensino regular. Entretanto, quando verticalizamos as analises para a etapa da educação infantil percebemos que a criança de 0 a 3 anos ainda é completamente desassistida legalmente desses direitos. 
As publicações das Reuniões Anuais da Anped durante as doze últimas edições, trouxeram pouco material referente à temática da inclusão na educação infantil, bem como sobre a formação inicial como momento importante de preparação profissional para atuar com as crianças EPAEE, talvez por ser um tema ainda com pouca representatividade nos meios acadêmicos ou entre os especialistas da área da Educação Especial.

O currículo da formação inicial e mais detidamente o estágio supervisionado não tem recebido a atenção dos pesquisadores na última década, especialmente quando focalizamos a inclusão de crianças EPAEE na educação infantil. Os resultados empíricos do estudo corroboram os achados nos documentos oficiais e nas pesquisas, pois se verificou além da escassez de matrícula de crianças EPAEE na educação infantil na rede municipal de ensino de Presidente Prudente, lacunas no currículo da formação inicial do pedagogo na FCT/Unesp para atuar nesse nível de ensino. Além disso, a fragilidade dos conhecimentos vistos na universidade e a dificuldade de resignifica-los à luz da experiência de inserção na instituição da educação infantil por meio da experiência de estágio evidencia o medo e a insegurança dos futuros professores para o exercício da docência, especialmente com crianças pequenas EPAEE.

Assim, converter a formação inicial num período fértil de reflexões e apropriação de conhecimentos (teórico-conceituais, práticos, atitudinais, entre outros) e num período de mudanças implica, segundo nossos respondentes, em: revisão do currículo da formação inicial interseccionando teoria e prática desde o início do curso; aproximação do conteúdo teórico com a realidade contemporânea; no reconhecimento de situações dilemáticas para a elaboração de planos de ação concretos; parcerias colaborativas entre a universidade e as instituições de educação infantil; reconhecimento do professor em exercício como um parceiro para o ensino prático da profissão, contato com situações reais de ensino na educação infantil, especialmente com crianças EPAEE incluídas etc. Quando formos capazes de operacionalizar essas mudanças acreditamos que teremos um valioso fator que propiciará a formação de profissionais mais bem preparados para o início da docência e menos desistência da profissão nos primeiros anos da carreira.

\section{REFERÊNCIAS}

BRASIL. Constituição (1988). Constituição da República Federativa do Brasil. Brasília, DF: Senado Federal: Centro Gráfico, 1988. 292 p.

. Lei 9394/96. Lei de Diretrizes e Bases da Educação Nacional. Disponível em $<w w w . m e c . g o v . b r>$. Acesso em: 07/10/2012 
. Resolução CNE/CP no 1, de 15 de Maio de 2006. Diário Oficial da União, Brasília, 16 de maio de 2006, Seção 1, p. 11. Disponível em < http://portal.mec.gov.br/cne/arquivos/pdf/rcp01_06.pdf>. Acesso em: 18 agos. 2013.

. MEC/SEESP. Política Nacional de Educação Especial na Perspectiva da Educação Inclusiva (versão preliminar) 2007. Disponível em < http://portal.mec.gov.br/seesp/arquivos/pdf/politica.pdf >. Acesso em: 08 fev. 2013.

. Plano Nacional de Educação. PNE no 10.172. Brasília: Senado Federal, 2001.

- Referencial curricular nacional para a educação infantil. Ministério da Educação e do Desporto, Secretaria de Educação Fundamental. - Brasília: MEC/SEF, 1998.

GUARANA, Deborah. O conceito histórico da infância. OVERMUNDO. Recife, PE, 2007. Disponível em: <http://www.overmundo.com.br/overblog/o-conceito-historico-da-infancia\#-overblog-6866>. Acesso em: 08 jan. 2013.

LEFEVRE, Fernando; LEFEVRE, Ana Maria. Depoimentos e Discursos: uma proposta de análise em pesquisa social. Brasília: Liberlivro, 2005.

ROSEMBERG, Fúlvia. Usos e abusos da obrigatoriedade na pré-escola. Caxambu: Trabalho Encomendado, 32a Reunião Anual da ANPEd, 2009.

SCHLÜNZEN, Elisa Tomoe Moriya; RINALDI, Renata Portela ; SANTOS, Danielle Ap. Nascimento. Inclusão escolar: marcos legais, atendimento educacional especializado e possibilidade de sucesso escolar para pessoas com deficiência. In: Caderno de Formação: formação de professores didática geral. São Paulo: Cultura Acadêmica, 2011, v. 9, p. 148-160.

TOZONI-REIS, Marília Freitas de Campos. Metodologia da Pesquisa Científica. Curitiba: IESDE Brasil, 2009. 